\title{
Chronic and oxidative stress association with total count of endothelial microvesicles in healthy young male plasma
}

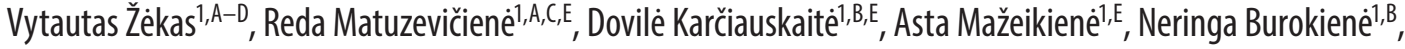

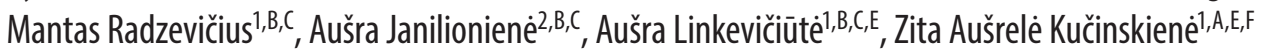 \\ ${ }^{1}$ Departament of Physiology, Biochemistry, Microbiology and Laboratory Medicine, Biomedicine Institute, Faculty of Medicine, Vilnius University, Lithuania \\ ${ }^{2}$ Center for Laboratory Medicine, Vilnius University Hospital Santaros Clinics, Lithuania
}

A - research concept and design; $B$ - collection and/or assembly of data; $C$ - data analysis and interpretation;

$D$ - writing the article; $E$ - critical revision of the article; $F$ - final approval of the article

Address for correspondence

Vytautas Žèkas

E-mail: vytautas.zekas@mf.vu.lt

\section{Funding sources \\ This work was supported by Research Council of Lithuania under grant [MIP-050/2015] \\ to Prof. Zita Kučinskienè. \\ Conflict of interest \\ None declared \\ Acknowledgements \\ Authors would like to acknowledge Dr. Audronė Jakaitiene for her statistical assistance in writing this article.}

Received on February 10, 2018

Reviewed on March 17, 2018

Accepted on August 9, 2018

Published online on January 31, 2019

Cite as

Žèkas V, Matuzevičienè R, Karčiauskaitè D, et al. Chronic and oxidative stress association with total count of endothelial microvesicles in healthy young male plasma. Adv Clin Exp Med. 2019;28(5):683-692. doi:10.17219/acem/94144

DOI

10.17219/acem/94144

\section{Copyright}

Copyright by Author(s)

This is an article distributed under the terms of the Creative Commons Attribution Non-Commercial License (http://creativecommons.org/licenses/by-nc-nd/4.0/)

\begin{abstract}
Background. Chronic and oxidative stress promotes injury to the endothelium. This happens early in the disease and novel biomarkers describing the rate of the damage may be important in early diagnostics and prevention. Microvesicles are shed from endothelial cells in response to oxidative stress, inflammation, coagulation, and angiogenesis. Their increased level in plasma could reflect the state of the endothelium.
\end{abstract}

Objectives. The objective of this study was to test the association between oxidative and chronic stress markers, atherosclerosis risk factors and endothelial microvesicle (EMV) count in peripheral blood.

Material and methods. The study included 81 males, aged 25-55 years and apparently healthy. Venous blood samples were labeled with anti-CD144-FITC, anti-CD105-BV421, anti-CD42a-PerCP, anti-CD62e-PE, anti-CD31-APCy7, and anti-CD61-APC (BD Biosciences, San Jose, USA), and tested using a BD LSR Fortessa cytometer (BD Biosciences). Events were gated on forward and side-scattered light parameters. Malondialdehyde (MDA) and cortisol concentrations were measured using high-performance liquid chromatography (HPLC).

Results. Four populations of EMV expressing a combination of $\mathrm{CD} 105^{+}, \mathrm{CD} 31^{+}, \mathrm{CD} 144^{+}$, and CD62e with $\mathrm{CD} 42 \mathrm{a}^{-}$or $\mathrm{CD} 42 \mathrm{a}^{+}$markers were examined. We found correlations between MDA concentration and hair cortisol and a total count of $\mathrm{CD} 144^{+}$microvesicles, and weak correlations with diastolic blood pressure (DBP) $(p=0.003, r=0.324)$ and systolic blood pressure (SBP) $(p=0.016, r=0.267)$, especially with the microvesicles carrying CD62e. There was a median difference of $\mathrm{CD} 105^{+}$microvesicle count between smoking $(n=13)$ and non-smoking $(n=68)$ individuals. A predictive model showed an association between CD144 microvesicle counts with cortisol and MDA concentrations and waist circumference.

Conclusions. In conclusion, our data and predictive model showed that the total counts of microvesicle populations were associated with stress-related parameters - cortisol and MDA concentrations; expression of CD62e in various populations of EMV and the ratio of CD144 ${ }^{+}$to $C D 105^{+} / \mathrm{CD} 62 \mathrm{e}^{+}$were associated with increased DBP and SBP, and also with total cholesterol concentration in healthy young male population.

Key words: flow cytometry, oxidative stress, atherosclerosis, dyslipidemia, microvesicles 


\section{Introduction}

Cardiovascular disease remains one of the main causes of death worldwide. Oxidative stress is implicated in atherosclerosis pathogenesis and caused by the production of excess reactive oxygen species (ROS) ${ }^{1}$. Reactive oxygen species are formed naturally and act as regulators of various cell functions and biological processes. Uncontrolled production of ROS is implicated in vascular injury. ${ }^{2}$ Endothelial dysfunction is known to be independently associated with cardiovascular mortality. ${ }^{3}$

Malondialdehyde (MDA) concentration in blood plasma is proposed as an effective oxidative stress biomarker. Most of this substance is produced during the reaction process of decomposition of products of lipid peroxidation and it helps to evaluate oxidative stress level in vascular system. ${ }^{4}$ On the other hand, cortisol concentration in hair could be used as a biomarker for chronic stress. ${ }^{5}$

Many cells, such as endothelial cells, white blood cells, platelets, and red blood cells, release microvesicles. These microvesicles are non-nuclear vesicles of various sizes between $100 \mathrm{~nm}$ and $1000 \mathrm{~nm}$, and they carry inside a variety of proteins and genetic material that may influence various intra- and inter-cellular processes. They also have specific membrane receptors that could help to regulate cellular response to the adjacent environment.

Microvesicles are shed from endothelial cells in response to various stimuli, such as oxidative stress, inflammation, coagulation, and angiogenesis. ${ }^{6}$ So far, the precise relationship of microvesicles with cell signaling systems is not known, but it is already clear that these are not just residual particles. $^{7}$ They could be viewed as mediators in various signaling pathways in response to stimuli. It is a promising idea to use microvesicle count in routine clinical practice as an early diagnostic biomarker. Endothelial microvesicles (EMV) may indicate atherosclerosis and its clinical manifestation - ischemic heart disease. ${ }^{8}$

Information regarding their importance in early atherosclerosis is still inconsistent, especially in relation to phenotypes of EMV.

The aim of this study was to examine the different populations of EMV and their association with atherosclerosis risk factors and chronic and oxidative stress markers in a young healthy male population.

\section{Material and methods}

\section{Subjects}

The study group consisted of 81 males aged 25-55 years of age and apparently healthy. Patients with any history of cardiac and chronic diseases, or prior stroke or venous thromboembolism, or under antithrombotic and antihypertensive treatment were excluded from the study. We did not include female subjects in our study, as males usually have earlier onset of disease than their female counterparts. ${ }^{9}$ This study design also allowed us to have a more homogenous population and more representative results, since biomarkers between sexes are slightly different. Informed and signed consent was obtained from all the subjects and the study protocol was approved by the local ethics committee of Vilnius University, Lithuania (permission No. 158200-15-807-319). The study was performed in accordance with the Helsinki Declaration. Signed informed consent forms were archived.

We measured the weight, waist circumference and height of the individuals, and collected data about smoking habits. We also used Beck depression inventory to measure their depression level. Laboratory tests, including complete blood count, concentration of C-reactive protein (CRP), glucose, total cholesterol, triglycerides (TG), high-density lipoprotein cholesterol (HDL-C), and low-density lipoprotein cholesterol (LDL-C) were performed using routine techniques.

To better show the association with smoking habits, we also decided to split individuals into 2 groups based on current smoking: 1 . smoking group $(\mathrm{n}=13) ; 2$. non-smoking group $(\mathrm{n}=68)$.

\section{Derivatization and high-performance liquid chromatography method for the determination of malondialdehyde in serum}

The concentration of MDA from serum was measured using a method published by Khoschsorur et al. ${ }^{10}$ The sample was prepared by cleaning it and derivatizing analyte with thiobarbituric acid (TBA) into detectable form, i.e., the MDA-TBA adduct. Malondialdehyde concentration was determined using a Shimadzu Nexera X2 UHPLC system (Shimadzu Corp., Kyoto, Japan). Chromatographic separation was achieved using an Agilent Poroshell 120 EC-C18 (2.7 $\mu \mathrm{m}, 3.0 \times 100 \mathrm{~mm}$; Agilent Technologies, Palo Alto, USA) reversed phase column with 40:60 (v/v) $50 \mathrm{mM}$ phosphate buffer ( $\mathrm{pH}$ 6.8) and methanol as mobile phase. The flow rate was $0.4 \mathrm{~mL} \mathrm{~min}^{-1}$. Fluorimetric detection was performed with excitation at $515 \mathrm{~nm}$ and emission at $553 \mathrm{~nm}$. The data was collected and processed using the LabSolutions software (Shimadzu Corp.).

\section{Extraction and analysis of cortisol in human hair}

The concentration of cortisol from hair was accomplished using an extraction method published by Raul et al. ${ }^{11}$ and De Palo et al. ${ }^{12}$ Hair samples were washed twice in $5 \mathrm{~mL}$ isopropanol. A $50 \mathrm{mg}$ of each sample were finely cut and incubated in $1.5 \mathrm{~mL}$ of Sorenson's buffer, $\mathrm{pH}$ 7.6, for $16 \mathrm{~h}$ at $40^{\circ} \mathrm{C}$, in the presence of $10 \mathrm{ng}$ of 6 - $\alpha$ methylprednisolone as internal standard. The incubation medium was centrifuged and the supernatant was transferred to SPE 
Table 1. Summary of endothelial biomarkers for flow cytometry analysis of endothelial microvesicles

\begin{tabular}{|c|c|c|}
\hline Marker & Function & Origin \\
\hline CD144 & VE-cadherin; responsible for angiogenesis and intercellular communication & endothelial cells \\
\hline CD105 & endoglin; important for angiogenesis & endothelial cells, macrophages \\
\hline CD31 & $\begin{array}{l}\text { platelet endothelial cell adhesion molecule (PECAM-1); important for angiogenesis and } \\
\text { integrin activation; associated with endothelial cell apoptosis }\end{array}$ & $\begin{array}{l}\text { platelets, endothelial cells, monocytes, } \\
\text { granulocytes, and B-cells }\end{array}$ \\
\hline CD62e & E-selectin; adhesion molecule, participates in inflammation and recruiting leukocytes & activated endothelial cells \\
\hline CD42a & $\begin{array}{l}\text { glycoprotein IX; it forms a 1-to-1 noncovalent complex with glycoprotein Ib, a platelet surface } \\
\text { membrane glycoprotein complex that functions as a receptor for the von Willebrand factor }\end{array}$ & platelets \\
\hline CD61 & $\begin{array}{c}\text { integrin subunit } \beta-3 \text {; integrins are known to participate in cell adhesion as well as cell-surface } \\
\text { mediated signaling }\end{array}$ & platelets \\
\hline
\end{tabular}

Discovery DSC-18 column (Sigma-Aldrich, St. Louis, USA), which was previously equilibrated (3 $\mathrm{mL} \mathrm{MeOH}$ followed by $1.5 \mathrm{~mL}$ of water). The succeeding steps were the following: washing with $0.5 \mathrm{~mL}$ of water followed by $0.5 \mathrm{~mL}$ of acetone/water $(1: 4, \mathrm{v} / \mathrm{v}), 0.25 \mathrm{~mL}$ of hexane and elution with $1.5 \mathrm{~mL}$ of diethyl ether. The finally obtained eluate was evaporated to dryness with nitrogen stream and the dry residue was resuspended using $100 \mu \mathrm{L}$ of acetonitrile/ water $(1: 1, \mathrm{v} / \mathrm{v})$. Cortisol concentration was determined by a Shimadzu Nexera X2 UHPLC system (Shimadzu Corp.). A 10-microliter volume of the extract was injected onto the Zorbax Eclipse XDGB-C8 column $(5.0 \mu \mathrm{m}$, $4.6 \times 150$ mm; Agilent Technologies). Each 20-min chromatographic run was carried out in a binary mobile phase of acetonitrile and deionized water $(40: 60, \mathrm{v} / \mathrm{v})$. The flow rate was $1.0 \mathrm{~mL} \mathrm{~min}^{-1}$. The UV absorbance was measured at $245 \mathrm{~nm}$. Data was collected and processed using the LabSolutions software (Shimadzu Corp.). Each sample was analyzed in triplicates.

\section{Blood sampling and preparation of platelet-poor plasma}

Blood samples were collected into tubes containing lithium heparin after night fasting. Tubes were centrifuged for $10 \mathrm{~min}$ at 3,000 g relative centrifugal force (RCF) within $1 \mathrm{~h}$ from collection to obtain platelet-free plasma. Three-quarters of the recovered plasma was transferred to a sterile tube and centrifuged again at 15,000 g RCF for $30 \mathrm{~min}$ in an angle head rotor to create a microvesicle pellet. The resulting pellet was reconstituted with $1 \mathrm{~mL}$ of serum-free freezing medium (Biological Industries, Beit HaEmek, Israel) containing dimethyl sulfoxide (DMSO) and analyzed using flow cytometry. We adhered to all health and safety procedures when handling clinical samples.

\section{Flow cytometry}

Samples were run on a BD LSR Fortessa II flow cytometer (BD Biosciences, San Jose, USA). Particle size gates were defined based on forward- and side-scattered light with polystyrene microbeads of known size. We used standard microbeads from Megamix-Plus (Bio-Cytex, Marseille, France) to determine the place of microvesicles smaller than $1 \mu \mathrm{m}$ on a dot plot. All samples were labeled with anti-CD144-FITC, anti-CD105-BV421, anti-CD42a-PerCP, anti-CD62e-PE, anti-CD31-APCy7, and anti-CD61-APC (BD Biosciences). All events were gated on a forward- vs side-scattered light dot plot according to their intensity (size). Each analysis included 1,000,000 events.

When constructing the panel of cellular markers for this study, we selected antigens that are highly expressed by endothelial cells to achieve the most precise microvesicle labeling. We took into account the specificity of every marker and its sensitivity in relation to EMV. A summary of the chosen markers is presented in Table 1.

We analyzed the size and granularity of EMV by forwardscattered light set to a logarithmic scale and side-scattered light set to a logarithmic scale. As shown in Fig. 1, the population of EMV was first identified according to their light-scattering characteristics, representing their relative size. The populations were analyzed for CD144, CD105, CD31, CD61, CD42a, and CD31 expression (Fig. 1).

We identified 4 distinctive EMV populations having these markers: $1 . \mathrm{CD} 105^{+}, \mathrm{CD} 42 \mathrm{a}^{-}$and $\mathrm{CD} 61^{-} ; 2 . \mathrm{CD} 144^{+}$, CD42 $\mathrm{a}^{-}$and $\mathrm{CD}^{-}$; 3. CD144 ${ }^{+}, \mathrm{CD} 42 \mathrm{a}^{+}$and $\mathrm{CD} 61^{-}$; and 4. $\mathrm{CD}^{+} 1^{+}, \mathrm{CD} 42 \mathrm{a}^{-}$and $\mathrm{CD}^{-} 1^{-}$. Furthermore, in each population we determined the percentage of EMV carrying CD62e.

\section{Cell culture}

In order to be sure that we gated on genuine EMV, we performed flow cytometry of EMV in cultured human endothelial cells. Human umbilical vein endothelial cells (HUVEC; Lonza, Basel, Switzerland) extracted from pooled donors were cultivated in complete endothelial cell growth media (EGM-2 BulletKit; Lonza) under standard cell culture conditions $\left(37^{\circ} \mathrm{C}, 5 \% \mathrm{CO}_{2}\right)$. Cells of passage $2-3$ were used when $90 \%$ confluent. Endothelial microvesicles were generated by growing cells in growth media conditioned with cyclophilin A (Abcam, Cambridge, UK). We formulated 4 different solutions with different cyclophilin A concentrations of $10 \mathrm{ng} / \mathrm{mL}, 20 \mathrm{ng} / \mathrm{mL}, 30 \mathrm{ng} / \mathrm{mL}$, and $60 \mathrm{ng} / \mathrm{mL}$, and incubated the cells for $24 \mathrm{~h}$. As a negative 

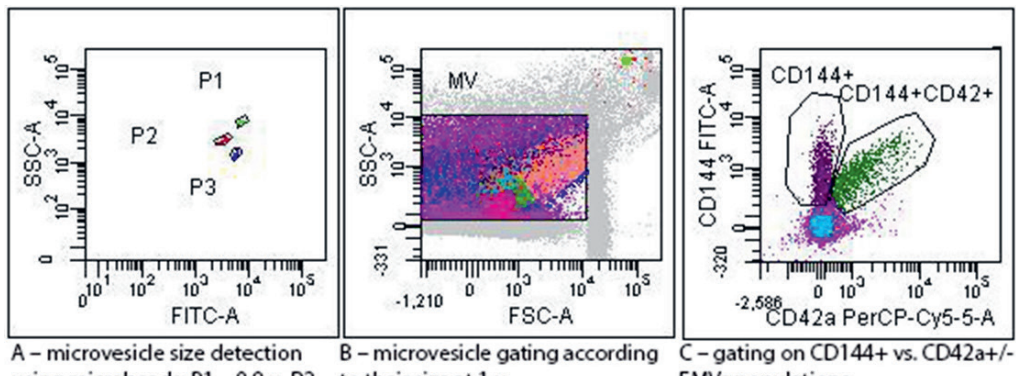

using microbeads: $\mathrm{P} 1-0.9 \mu, \mathrm{P} 2-$ to their size at $1 \mu$ $0.3 \mu, P 3-0.5 \mu$
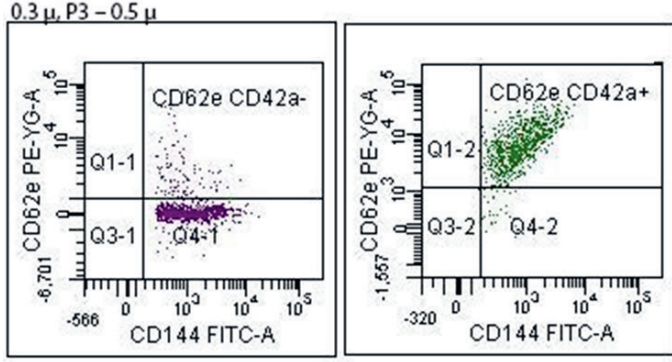

EMVs populations

$$
\begin{aligned}
& \text { D-gating on } \\
& \text { CD62e+ EMVs }
\end{aligned}
$$

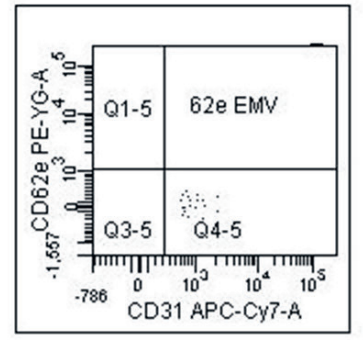

$G$ - gating $\mathrm{CD} 31+, \mathrm{CD} 42 \mathrm{a}-$ and CD61-EMVs
Fig. 1. Flow cytometric analysis of endothelial-derived microvesicles from plasma

A - microvesicle size detection using microbeads: P1 - $0.9 \mu \mathrm{m}$, P2 - $0.3 \mu \mathrm{m}, \mathrm{P} 3-0.5 \mu \mathrm{m} ; \mathrm{B}-$ microvesicle gating according to their size at $1 \mu \mathrm{m} ; \mathrm{C}$ - gating on CD144+ vs CD42a $a^{+/-}$EMVs populations; D - gating on $\mathrm{CD}_{144^{+}}, \mathrm{CD} 42 \mathrm{a}^{-}$and $\mathrm{CD} 62 \mathrm{e}^{+} \mathrm{EMV}$; $\mathrm{E}$ - gating on $\mathrm{CD} 144^{+}, \mathrm{CD} 42 \mathrm{a}^{+}$and $\mathrm{CD} 62 \mathrm{e}^{+} \mathrm{EMVs} ; \mathrm{F}$ - gating on CD62e $e^{+}$vs CD105 ${ }^{+}$EMVs; $G$ - gating on CD31 ${ }^{+}, \mathrm{CD}^{2} 2 \mathrm{a}^{-}$ and $\mathrm{CD}^{-}{ }^{-}$EMVs. control, we used cells cultivated in the same conditions without cyclophilin A. Supernatant from cell cultures was collected and then centrifuged at 15,000 g RCF for 30 min to yield a pellet of microvesicles. The pellet was re-suspended in $1 \mathrm{~mL}$ serum-free freezing medium containing DMSO and analyzed with flow cytometer using our panel of antibodies.

\section{Statistical analysis}

The Shapiro-Wilk test was used for normal distribution of continuous variables. Results are presented as means and standard deviations (SD) or as medians (Me) and interquartile ranges (IQR) depending on variable distribution. Correlations between 2 continuous variables were performed using Pearson's correlation coefficients; otherwise the Spearman's correlation coefficients were used. Differences in means between normally distributed continuous variables were found using a t-test. The Wilcoxon rank-sum test (Mann-Whitney $U$ test) was used to find median difference between non-normal distributed continuous variables. A multiple linear regression analysis was employed to evaluate the influence of several independent variables (waist circumference, hair cortisol and MDA concentrations, total count of EMV positive for CD144 and CD42a and total count of EMV positive for
CD31) on $\mathrm{CD}_{144}{ }^{+}, \mathrm{CD} 42 \mathrm{a}^{-}$and $\mathrm{CD} 61^{-}$microvesicle count. The significance level for the test was set at 0.05. Statistical analysis was carried out using $\mathrm{R}$ statistical software v. 1.0.136 and SPSS v. 21 (IBM Corp., Armonk, USA).

\section{Results}

\section{Clinical characteristics}

Demographic and clinical data are displayed in Table 2. Diastolic blood pressure (DBP), heart rate and MDA concentration were distributed normally.

Total counts of populations of microvesicles were quantified using flow cytometry and expressed as microvesicles $/ \mu \mathrm{L}$. The characteristics of all 4 populations of $\mathrm{mi}-$ crovesicles are presented in Table 3.

\section{Association of atherosclerosis risk factors with $\mathrm{CD} 144^{+}$or $\mathrm{CD} 105^{+}$or $\mathrm{CD} 31^{+}$ and $C D 42 \mathrm{a}^{-}$or CD42a+, and CD61- endothelial microvesicles populations}

The total count of EMV carrying CD105 ${ }^{+}, \mathrm{CD}_{42 \mathrm{a}^{-}}$and $\mathrm{CD}^{-} 1^{-}$had a weak correlation with systolic blood pressure (SBP) ( $\mathrm{r}=0.23 ; \mathrm{p}=0.036)$ (Fig. 2). We also compared 
Table 2. Demographic and clinical characteristics of the population studied. The data values are presented as means and standard deviations (SD) or as medians and interquartile range (IQR) depending on variable distribution

\begin{tabular}{|c|c|}
\hline Variables & Median (IQR) or means (SD) \\
\hline Age [years] & $\begin{array}{c}\text { interval: } 25-55 \\
\text { median (IQR): } 33 \text { (16) }\end{array}$ \\
\hline CRP $[\mathrm{mg} / \mathrm{L}]$ & median (IQR): 0.52 (0.78) \\
\hline $\mathrm{LDL}-\mathrm{C}[\mathrm{mmol} / \mathrm{L}]$ & median (IQR): 3.06 (0.93) \\
\hline $\mathrm{HDL}-\mathrm{C}[\mathrm{mmol} / \mathrm{L}]$ & median (IQR): 1.19 (0.32) \\
\hline TG concentration [mmol/L] & median (IQR): 1.17 (0.93) \\
\hline $\mathrm{SBP}[\mathrm{mm} \mathrm{Hg}]$ & median (IQR): 130 (13) \\
\hline $\mathrm{DBP}[\mathrm{mm} \mathrm{Hg}]$ & means (SD): 80.11 (0.99) \\
\hline Heart rate [bpm] & means (SD): 71.00 (1.42) \\
\hline Total cholesterol [mmol/L] & median (IQR): 4.99 (1.24) \\
\hline Glucose [mmol/L] & median (IQR): 5.21 (0.51) \\
\hline Waist circumference [cm] & median (IQR): 88 (17) \\
\hline BMI $\left[\mathrm{kg} / \mathrm{m}^{2}\right]$ & median (IQR): 24.25 (4.41) \\
\hline Malondialdehyde concentration & means (SD): 99.6 (2.78) \\
\hline Hair cortisol concentration & median (IQR): 19.82 (37.03) \\
\hline
\end{tabular}

CRP - C-reactive protein; LDL-C - low-density lipoprotein cholesterol; $\mathrm{HDL}-\mathrm{C}$ - high-density lipoprotein cholesterol; TG - triglyceride; SBP - systolic blood pressure; DBP - diastolic blood pressure; BMI - body mass index.

medians of total count of CD105 ${ }^{+}$EMV between the groups of non-smokers and smokers. In the group of non-smokers, the median of the total count of $\mathrm{CD} 105^{+}, \mathrm{CD}_{2} 2 \mathrm{a}^{-}$and $\mathrm{CD}^{-} 1^{-}$microvesicles was 10.11 microvesicles/ $\mu \mathrm{L}$ and in the group of smokers it was 64.78 microvesicles $/ \mu \mathrm{L}(\mathrm{p}=0.04)$. Smoking was not an independent risk factor since we also found a difference of medians of TG concentration $(\mathrm{p}=0.048)$ and CRP concentration $(\mathrm{p}=0.005)$ between the groups of smokers and non-smokers. The total count of these EMV also correlated with cortisol concentration in hair $(\mathrm{r}=0.25, \mathrm{p}=0.03)$, but had no correlation with MDA concentration in blood serum.

Externalization of CD62 $\mathrm{e}^{+}$in this EMV population was associated with TG level, as the percentage of CD62 $\mathrm{e}^{+}$microvesicles had a weak but statistically significant correlation with TG concentration $(\mathrm{r}=0.28, \mathrm{p}=0.015)$. Unlike CD105 ${ }^{+}$microvesicles, these microvesicles correlated with MDA concentration in blood serum $(r=0.27, p=0.01)$, indicating the relationship of externalization of CD62e in this microvesicle subset and oxidative stress. Other characteristics had no significant correlation.

The total count of $\mathrm{CD} 144^{+}$and $\mathrm{CD} 61^{-}$microvesicles correlated with MDA concentration $(\mathrm{r}=0.27, \mathrm{p}=0.02)$ and cortisol concentration in hair $(r=0.29, p=0.01)$. Since during our research we found 2 subsets of these microvesicles, one positive for CD42a and another not, we analyzed these 2 subsets separately. The total count of CD144+, CD42aand $\mathrm{CD}^{-} 1^{-}$microvesicles correlated with both MDA concentration $(\mathrm{r}=0.34, \mathrm{p}=0.003)$ and cortisol concentration in hair $(\mathrm{r}=0.34, \mathrm{p}=0.03)$. Hair cortisol concentration also correlated with the CD144 $4^{+}, \mathrm{CD} 42 \mathrm{a}^{+}$and $\mathrm{CD} 61^{-}$subset $(\mathrm{r}=0.33, \mathrm{p}=0.03)$. It could indicate that only CD42a- EMV could have an association with oxidative stress. The expression of CD62e in this population was, however, associated with high DBP $(\mathrm{p}=0.025, \mathrm{r}=0.25)$, with the total cholesterol level ( $\mathrm{p}=0.048, \mathrm{r}=0.28)$ (Fig. 2) and also with the depression level $(\mathrm{p}=0.003, \mathrm{r}=0.33)$. We measured the depression level as a continuous variable. It has to be mentioned that depression had no association with hair cortisol or MDA concentrations. Externalization of CD62e in both subsets also did not correlate with either MDA or hair cortisol concentrations.

Table 3. Characteristics of the populations of microvesicles presented as medians (Me) and interquartile range (IQR)

\begin{tabular}{|c|c|c|}
\hline Microvesicle populations & $\begin{array}{l}\text { Microvesicle count [microvesicles/ } \mu \mathrm{L} \text { ] } \\
\text { Median and quartiles }(\mathrm{Q})\end{array}$ & $\begin{array}{c}\text { CD62e expression [\%] } \\
\text { Median and quartiles (Q) }\end{array}$ \\
\hline $\mathrm{CD}_{105}{ }^{+}, \mathrm{CD} 42 \mathrm{a}^{-}$and $\mathrm{CD} 61^{-}$ & $\begin{array}{c}\min =0 \\
\mathrm{Q} 1=1.9 \\
\mathrm{Me}=15.52 \\
\mathrm{Q} 3=76.16 \\
\max =1507.53\end{array}$ & $\begin{array}{c}\min =0 \\
\mathrm{Q} 1=0 \\
\mathrm{Me}=1.6 \\
\mathrm{Q} 3=4.95 \\
\max =25\end{array}$ \\
\hline $\mathrm{CD}_{144^{+}}, \mathrm{CD}_{42 \mathrm{a}^{-}}$and $\mathrm{CD} \mathrm{1}^{-}$ & $\begin{array}{c}\min =24.3 \\
\mathrm{Q} 1=139.14 \\
\mathrm{Me}=308.6 \\
\mathrm{Q} 3=418.75 \\
\max =896.74\end{array}$ & $\begin{array}{c}\min =0 \\
\mathrm{Q} 1=2.35 \\
\mathrm{Me}=5.8 \\
\mathrm{Q} 3=8.3 \\
\max =16.2\end{array}$ \\
\hline $\mathrm{CD}_{144}{ }^{+}, \mathrm{CD}_{42 \mathrm{a}^{+}}$and $\mathrm{CD} 1^{-}$ & $\begin{array}{c}\min =90.73 \\
\mathrm{Q} 1=200.11 \\
\mathrm{Me}=274.42 \\
\mathrm{Q} 3=394.95 \\
\max =975.57\end{array}$ & $\begin{array}{l}\min =0.9 \\
\mathrm{Q} 1=12.75 \\
\mathrm{Me}=50.7 \\
\mathrm{Q} 3=97.15 \\
\max =100\end{array}$ \\
\hline $\mathrm{CD}_{1} 1^{+}, \mathrm{CD} 42 \mathrm{a}^{-}$and CD61- & $\begin{array}{c}\min =0 \\
\mathrm{Q} 1=0 \\
\mathrm{Me}=1.15 \\
\mathrm{Q} 3=2.8 \\
\max =17.91\end{array}$ & - \\
\hline
\end{tabular}



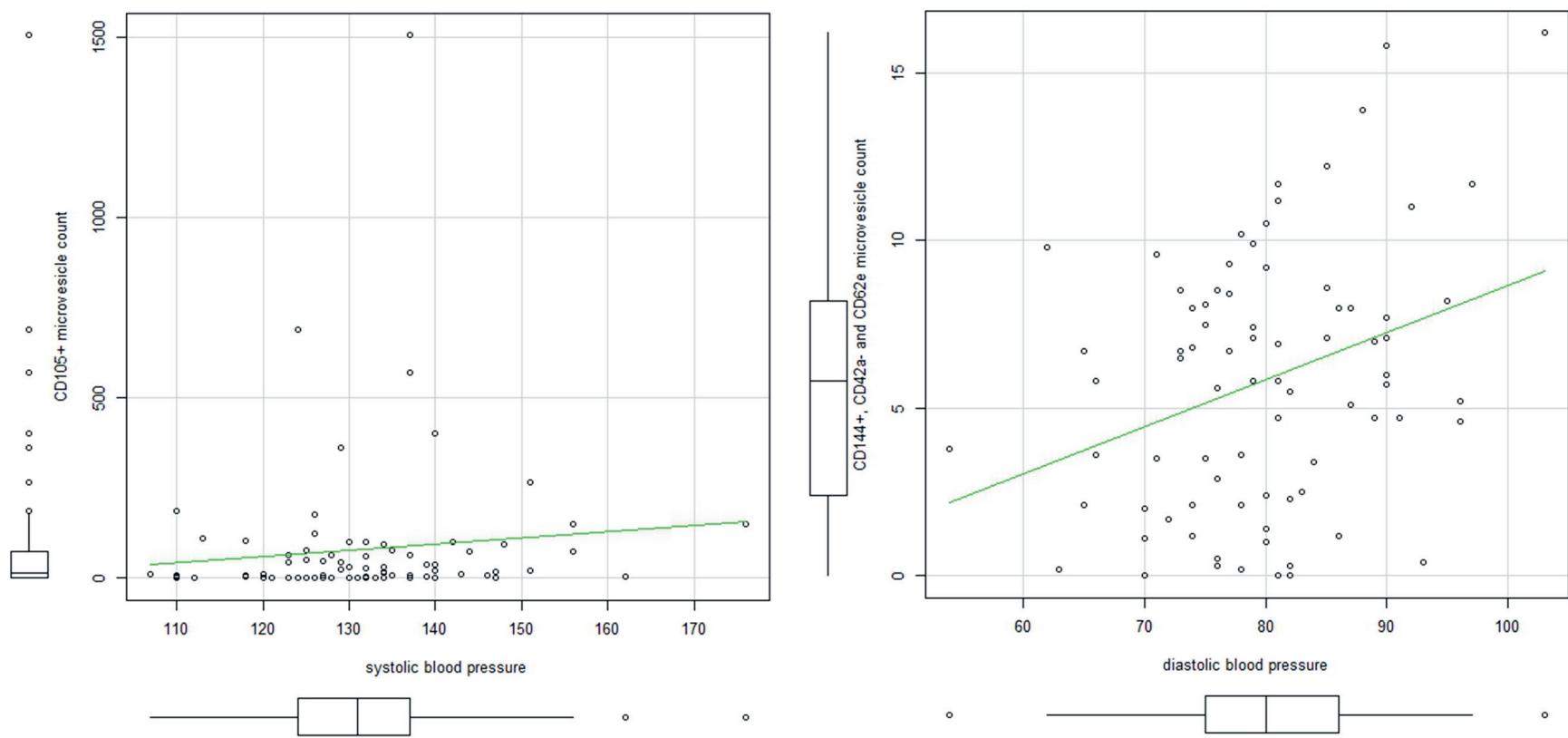

Fig. 2. Correlation of EMV carrying CD144, CD62e or CD105 with SBP and DBP. Marginal boxplots in this graph represent the lower quartile (Q1), median (Q2) and upper quartile of the sample data (horizontal boxplots represents blood pressure, vertical - total EMV count). The ends of the whiskers represent the lowest datum still within 1.5 IQR of the lower quartile and the highest datum still within 1.5 IQR of the upper quartile. Outliers have not been excluded and are shown here as dots

Table 4. Correlations between different populations of endothelial microvesicles (EMV)

\begin{tabular}{|c|c|c|c|}
\hline Populations of EMV & $\mathrm{CD}_{105^{+}}, \mathrm{CD}^{-} 1^{-}$and $\mathrm{CD} 42 \mathrm{a}^{-}$ & $\mathrm{CD} 1^{+}, \mathrm{CD} 1^{-}$and $\mathrm{CD} 42 \mathrm{a}^{-}$ & $\mathrm{CD}_{144^{+}}, \mathrm{CD} 1^{-}$and $\mathrm{CD} 42 \mathrm{a}^{+}$ \\
\hline $\mathrm{CD}_{144^{+}}, \mathrm{CD}^{-} 1^{-}$and $\mathrm{CD} 42 \mathrm{a}^{-}$ & $r=0.26, p=0.017$ & $r=0.35, p=0.001$ & $r=0.67, p<0.001$ \\
\hline $\mathrm{CD}_{144^{+}}, \mathrm{CD} 1^{-}$and CD42a+ & - & $r=0.5, p<0.001$ & - \\
\hline
\end{tabular}

Total count of CD31+, CD61- and CD42a- had an association with age $(\mathrm{p}=0.017, \mathrm{r}=0.29)$.

Other investigated risk factors such as body mass index (BMI), CRP concentration, glucose concentration, heart rate and dyslipidemia had no significant associations with numbers of endothelial microvesicles. Hair cortisol concentration was not associated with MDA concentration. On the other hand, both of them correlated with total cholesterol concentration $(\mathrm{r}=0.24, \mathrm{p}=0.04$ for hair cortisol and $\mathrm{r}=0.39, \mathrm{p}<0.001$ for MDA concentration) and waist circumference $(\mathrm{r}=0.25, \mathrm{p}=0.02$ for MDA concentration and $\mathrm{r}=0.33, \mathrm{p}=0.003$ for hair cortisol). Hair cortisol was associated with CRP $(r=0.24, \mathrm{p}=0.04)$ and $\mathrm{DBP}(\mathrm{r}=0.26$, $\mathrm{p}=0.02)$ and MDA concentration had correlation with LDL-C $(\mathrm{r}=0.33, \mathrm{p}=0.003)$ and BMI $(\mathrm{r}=0.24, \mathrm{p}=0.03)$. This was an expected result, since BMI correlated with LDL-C $(r=0.28, p=0.01)$, but there was no correlation between CRP and DBP indicating hair cortisol concentration as an independent variable.

\section{Relation between the microvesicle populations}

The 4 different EMV populations were interrelated. There was a strong correlation between those carrying
$\mathrm{CD}_{105}{ }^{+}, \mathrm{CD} 42 \mathrm{a}^{-}$and $\mathrm{CD} 61^{-}$and those carrying CD144 ${ }^{+}$, CD42a $\mathrm{a}^{-}$and $\mathrm{CD}^{-} 1^{-}(\mathrm{r}=0.5, \mathrm{p}<0.001)$. Furthermore, the count of $\mathrm{CD} 105^{+}$microvesicles weakly correlated with CD $144^{+}$and CD $42 \mathrm{a}^{+}$microvesicles $(\mathrm{r}=0.29, \mathrm{p}=0.009)$, indicating a connection between these 3 populations. Details of correlations between populations of EMV are presented in Table 4.

We also calculated ratios between different subsets of EMV and found that a higher ratio between subset of microvesicles carrying CD144 and subset of microvesicles carrying both CD105 and CD62e correlated with total cholesterol concentration $(\mathrm{r}=0.29, \mathrm{p}=0.02)$ and high LDL-C concentration $(\mathrm{r}=0.25, \mathrm{p}=0.042)$.

\section{Regression analysis of the association between total count of $\mathrm{CD}_{144^{+}}$and CD42a- endothelial microvesicles, and chronic and oxidative stress markers}

Multiple variable analyses were conducted to examine the relationship between EMV carrying CD144 and not expressing CD42a and CD61 antigens on their membrane, and potential predictors, such as waist circumference, hair cortisol and MDA concentrations, total count of microvesicles carrying both CD144 and CD42a, and 
Table 5. Regression model characteristics using CD144+ ${ }^{+}, \mathrm{CD} 42 \mathrm{a}^{-}$and CD61- microvesicle count as dependent variables, and waist circumference, hair cortisol and malondialdehyde (MDA) concentrations, total count of endothelial microvesicles (EMV) positive for CD144 and CD42a and total count of EMV positive for CD31 as independent predictors

\begin{tabular}{|l|c|c|c|c|}
\hline \multicolumn{1}{|c|}{ Variable } & Unstandardized coefficient & $\mathrm{p}$-value & Significance & $95 \%$ confidence intervals \\
\hline Hair cortisol concentration & -0.36 & 0.17 & 0.038 & $-0.71 ;-0.02$ \\
\hline Waist circumference & 3.76 & 1.42 & 0.009 & $0.93 ; 6.59$ \\
\hline MDA concentration & -1.32 & 0.62 & 0.039 & $-2.56 ;-0.07$ \\
\hline Total count of CD144 ${ }^{+}, \mathrm{CD} 42 \mathrm{a}^{+}$and $\mathrm{CD} 61^{-}$populations & 0.59 & 0.08 & $<0.001$ & $0.42 ; 0.75$ \\
\hline Total count of $\mathrm{CD} 31^{+}, \mathrm{CD} 42 \mathrm{a}^{-}$and $\mathrm{CD} 61^{-}$populations & 13.11 & 4.27 & 0.003 & $4.60 ; 21.63$ \\
\hline
\end{tabular}

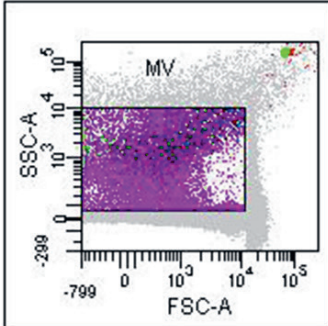

A - microvesicle gating according to their size at $1 \mu$

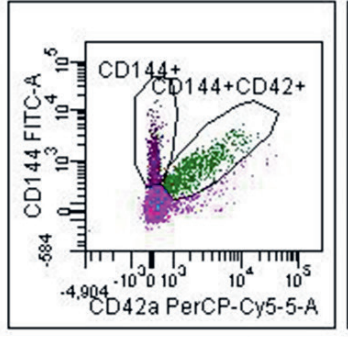

B - gating CD144+ and CD42a+/-EMV populations

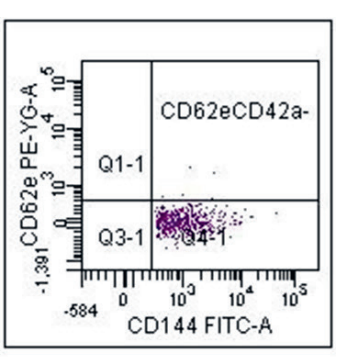

C- gating CD144+, CD42aCD62e+ EMVs

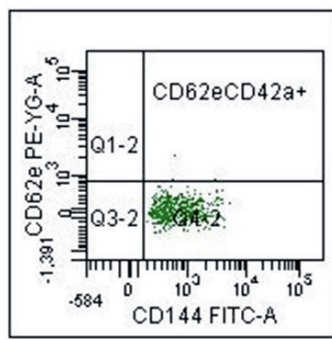

D - gating CD144+, CD42a+, CD62e+ EMVs

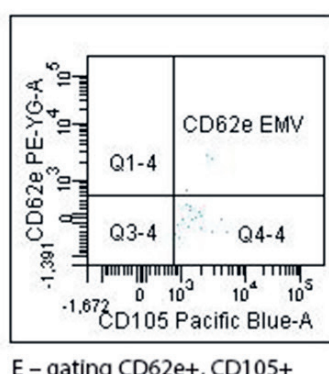

EMVs from total of CD105+

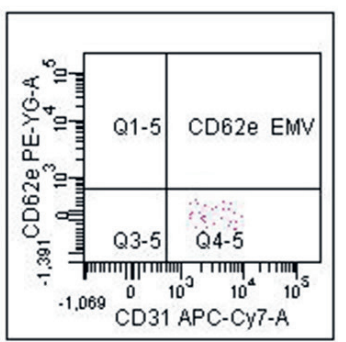

F - gating $\mathrm{CD} 31+, \mathrm{CD} 42 \mathrm{a}-$,

CD61-, CD62e+ EMVs
Fig. 3. Detection of EMV using flow cytometry in supernatant of endothelial cells without cyclophilin A

A - microvesicle gating according to their size at $1 \mu \mathrm{m}$; B - gating on CD144+ and CD42a ${ }^{+/-}$EMV populations;

C - gating on CD144+, CD42a- and CD62e $\mathrm{e}^{+}$EMV populations; $\mathrm{D}$ - gating on CD144+, CD42a $\mathrm{a}^{+}$and $\mathrm{CD} 62 \mathrm{e}^{+}$EMV populations; $\mathrm{E}$ - gating on $\mathrm{CD}_{2} \mathrm{e}^{+}$and $\mathrm{CD} 105^{+} \mathrm{EMV}$ populations from total of CD105+ EMVs; F - gating on CD31+, CD42a-, CD61and CD62 $\mathrm{e}^{+}$EMV populations. the total count of microvesicles carrying CD31. Waist circumference, total count of microvesicles carrying CD144 and CD42a, and microvesicles carrying CD31 positively correlated with the criterion, indicating that those with higher counts of CD144+ microvesicles tend to have a larger waist, higher CD144 ${ }^{+}, \mathrm{CD} 42 \mathrm{a}^{+}$and $\mathrm{CD}^{-} 1^{-}$microvesicle count, and a higher $\mathrm{CD} 31^{+}$microvesicle count. Hair cortisol and MDA concentrations negatively correlated with the criterion stating that higher hair cortisol and MDA concentrations are associated with lower CD144 ${ }^{+}, \mathrm{CD} 42 \mathrm{a}^{-}$ and $\mathrm{CD}^{-} 1^{-}$microvesicle count. The multiple regression model with all 5 predictors produced $\mathrm{r}=0.55$ and $\mathrm{p}<0.001$. As it can be seen in Table 5, waist circumference and the total count of microvesicles carrying CD144 and CD42a had a significant positive regression weights, indicating that subjects with larger waist circumference and a higher total count of microvesicles carrying CD144 and CD42a were expected to have a higher count of CD144 ${ }^{+}, \mathrm{CD} 42 \mathrm{a}^{-}$ and $\mathrm{CD}^{-} 1^{-} \mathrm{EMV}$ after controlling for the other variables in the model. Adding smoking as a predictor improved the model further $(\mathrm{r}=0.58, \mathrm{p}<0.001)$, indicating that smoking individuals should have higher microvesicle counts.

\section{Testing endothelial microvesicles in cell culture}

We observed 4 different populations of EMV in vitro, which corresponded to results in vivo (Fig. 3,4). Treated with cyclophilin A, endothelial cells released more EMV than those that grew in resting conditions by a maximum of 2-fold. We have to note that cells grown in higher than $10 \mathrm{ng} / \mathrm{mL}$ cyclophilin A concentration released less EMV than those grown in non-cyclophilin A-treated media (negative control). It is possible that there were fewer cells in those concentrations due to the fact that cyclophilin A is a strong apoptosis agent. ${ }^{13}$ There was no significant difference between the results of experiments in vivo and in vitro.

\section{Discussion}

Using different endothelial markers in this study, we detected 4 different EMV populations and found association between cortisol concentration in hair, MDA 


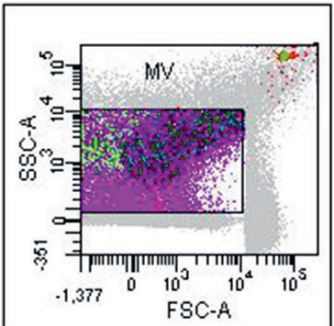

A - microvesicle gating according to their size at $1 \mu$

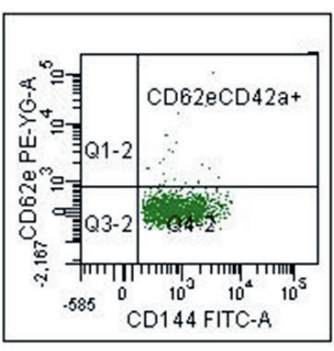

D - gating CD144+, $\mathrm{CD} 42 \mathrm{a}+, \mathrm{CD} 62 \mathrm{e}+\mathrm{EMVs}$

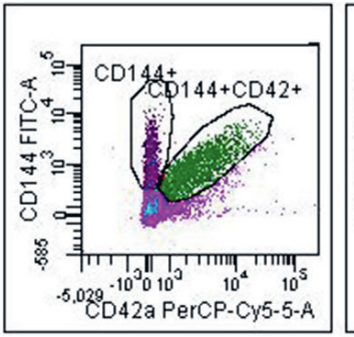

$B$ - gating CD144+ and CD42a+/-EMV populations

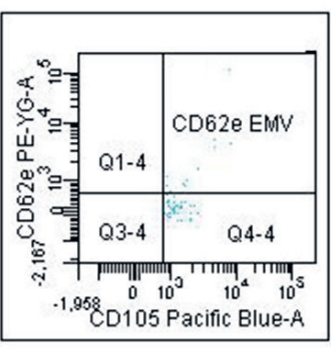

E - gating $\mathrm{CD} 62 \mathrm{e}+, \mathrm{CD} 105+$ EMVs from total of CD105+

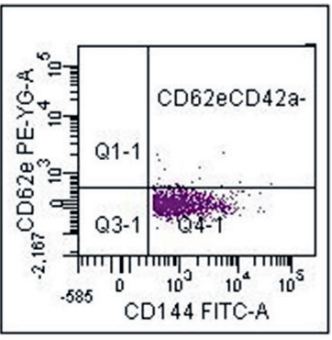

$C$ - gating $\mathrm{CD} 144+, \mathrm{CD} 42 \mathrm{a}-$ CD62e+ EMVs

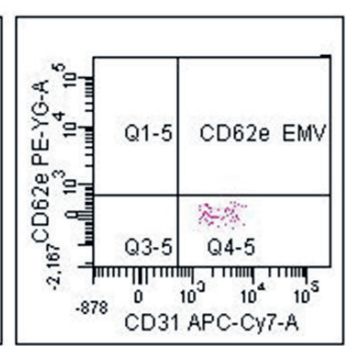

F - gating $\mathrm{CD} 31+, \mathrm{CD} 42 \mathrm{a}-$ CD61-, CD62e+ EMVs
Fig. 4. EMV detection using flow cytometry in supernatant of cyclophilin A-affected endothelial cells

A - microvesicle gating according to their size at $1 \mu \mathrm{m}$

$\mathrm{B}$ - gating on $\mathrm{CD}_{144^{+}}$and $\mathrm{CD} 42 \mathrm{a}^{+/-}$EMV populations;

C - gating on CD144 ${ }^{+}, \mathrm{CD} 42 \mathrm{a}^{-}$and CD62 $\mathrm{e}^{+}$EMV populations;

$\mathrm{D}$ - gating on $\mathrm{CD}_{144}{ }^{+}, \mathrm{CD} 42 \mathrm{a}^{+}$and $\mathrm{CD} 62 \mathrm{e}^{+} \mathrm{EMV}$ populations;

$\mathrm{E}$ - gating on $\mathrm{CD}_{2} \mathrm{e}^{+}$and $\mathrm{CD} 105^{+} \mathrm{EMV}$ populations from total of CD105+ EMVs; F - gating on CD31+ ${ }^{+}, \mathrm{CD}_{2} 2 \mathrm{a}^{-}, \mathrm{CD}^{-} 1^{-}$, and CD62 $\mathrm{e}^{+}$EMV populations. concentration in blood and total counts of microvesicle populations. Also, the levels of CD62e-positive microvesicles were higher in individuals with cardiovascular risk factors. There are studies that used markers mentioned in this study to research diabetes, ${ }^{14}$ neurodegeneration and ischemic stroke, ${ }^{15}$ and chronic heart failure. ${ }^{16}$ These studies identified different microvesicle populations that appeared to have different associations with disease prediction. To improve our results, we used all of these markers to better describe EMV and their populations.

Studies have shown the association of microvesicles positive for CD144 with high SBP. ${ }^{17}$ Microvesicles carrying $\mathrm{CD} 144^{+}$and $\mathrm{CD} 41 \mathrm{a}^{-}$or $\mathrm{CD} 31^{+}$and $\mathrm{CD} 41^{-}$were found to be associated with ischemic stroke and significantly correlated with stroke intensity. ${ }^{18}$ In our study, we found an association between the expression of CD62e in this population of these microvesicles and DBP, but not SBP. Interestingly, we detected 2 subsets of $\mathrm{CD} 144^{+}$microvesicles, one carrying a thrombocytic marker CD42a and another not carrying it. To check our results, we compared our findings in vivo with findings in vitro by investigating microvesicles collected from the cell culture. The release of both subsets of CD144+ microvesicles (containing and lacking CD42a) from healthy and damaged cells indicates that the endothelium release of microvesicles of a bi-lineal origin is possible. There is 1 clinical study where microvesicles of a bi-lineal origin carrying both CD62e and CD41 biomarkers were observed in patients having essential thrombocytemia. ${ }^{19}$ This study concluded that bi-lineal microvesicles suggested ongoing endothelial activation, since their number was associated with increased levels of mature von Willebrand factor (vWF). When analyzing for association of MDA concentration $(r=0.29, p=0.01)$ and hair cortisol concentration with total counts of microvesicle populations expressing CD144, we found that only the total count of CD144 $4^{+}, \mathrm{CD} 42 \mathrm{a}^{-}$and $\mathrm{CD} 61^{-}$microvesicles had a significant correlation with both MDA and cortisol concentration in hair. This does not prove to be true for the $\mathrm{CD} 144^{+}, \mathrm{CD} 42 \mathrm{a}+$ and $\mathrm{CD} 61^{-}$subset. These findings indicate that only CD42a- EMV could have a connection with oxidative or chronic stress. Since CD42a+ microvesicles had no association with either clinical or laboratory markers, they could have no importance as a disease biomarker. A weak correlation with depression level could indicate a possible connection of this marker with the psychological state of an individual, but there was no association with hair cortisol concentration. In comparison, CD144 $4^{+}$and CD42a- EMV was associated with depression level and hair cortisol concentration. The regression model does contain both subsets of CD144+ $4^{+}$icrovesicles and it would seem that an increase of CD42 $\mathrm{a}^{+}$subset also increases CD42asubset in oxidative environment. Increased hair cortisol and MDA concentration according to the model indicated lower CD $144^{+}$microvesicle count. This could be interpreted as a negative correlation between oxidative stress and $\mathrm{CD} 144^{+}$microvesicle count, including both CD42a ${ }^{+}$ and $C D 42 \mathrm{a}^{-}$microvesicles. Studies show that at least in cell culture, extracellular vesicles could communicate protective messages in oxidative stress. ${ }^{20}$

Another investigated marker in our study was CD105 (endoglin). It belongs to a family of angiogenesis, stimulating adhesion molecules, which are found mainly on the endothelial cell membrane. It is related to revascularization and has been found to be able to influence inflammation in the arterial wall. ${ }^{21}$ CD105 is highly expressed in unstable plaques and increased expression of this molecule could have a negative prognostic value. ${ }^{22}$ Our data showed that an increased total count of CD $105^{+}$EMV correlated positively with high SBP, but not DBP, as it was in the case of $\mathrm{CD} 144^{+}$microvesicles. There was also a difference 
in the medians of the total count of these microvesicles between smokers and non-smokers. In 1 study, an association between smoking and increased levels of CD62e positive microvesicles was found in healthy volunteers. ${ }^{23}$ Our study showed that non-activated microvesicles carrying CD105, but not CD144, were associated with smoking. We also found that the percentage of CD105-positive EMV carrying CD62e had a weak positive correlation with high blood TG concentration. Interestingly, the total count of microvesicles carrying CD144 had no association with the total cholesterol or LDL-C concentrations, but their total count ratio with those EMV having CD105 and CD62e on their membrane did. Some studies show that the CD $62 \mathrm{e}^{+}$to $\mathrm{CD} 31^{+}$microvesicles ratio was higher in healthy controls compared to metabolic syndrome patients and that biomarkers of biomechanical stress (NT-proBNP) and inflammation (hs-CRP, osteoprotegerin) were associated with a decreased $\mathrm{CD}_{2} \mathrm{E}^{+}$to $\mathrm{CD} 31^{+} /$annexin $\mathrm{V}^{+}$ratio. ${ }^{24}$ It is known that elevated CD62e-positive microvesicles can be associated with endothelial activation. ${ }^{25}$ These results suggest that activated EMV could be more sensitive markers for endothelial dysfunction determination.

The association between MDA concentration and $\mathrm{CD}_{105}{ }^{+}$and $\mathrm{CD} 62 \mathrm{e}^{+}$microvesicles was also evident, adding to the fact that there exists a link between oxidative stress and externalization of CD62e in CD105 EMV. This connection with MDA concentration was also detected between $\mathrm{CD}_{144}{ }^{+}, \mathrm{CD} 42 \mathrm{a}^{-}$and $\mathrm{CD} 61^{-}$microvesicle population, indicating an interesting link between the total count of $\mathrm{CD} 144^{+}$microvesicles and $\mathrm{CD} 105^{+}$as well as $\mathrm{CD} 62 \mathrm{e}^{+}$ microvesicles in oxidative stress. It is possible that both of these populations of microvesicles are associated with oxidative stress.

According to the literature, $\mathrm{CD} 31^{+}$microvesicles are possibly associated with endothelial cell apoptosis, while CD $144^{+}$microvesicles are possibly associated with endothelial cell activation. ${ }^{26}$ In our study, we only found a weak correlation between these microvesicles and age. It was not a surprising result, since the investigated individuals were relatively healthy. On the other hand, when evaluating regression model, the total count of $\mathrm{CD} 31^{+}$ microvesicles correlated positively with the total counts of $\mathrm{CD} 144^{+}, \mathrm{CD} 42 \mathrm{a}^{-}$and $\mathrm{CD} 61^{-}$populations. It suggests that the increase of $\mathrm{CD} 31^{+}$microvesicles causes also an increase of $\mathrm{CD} 144^{+}$microvesicles. This data could be interpreted as a possible connection between endothelial activation and apoptosis in oxidative stress and should be tested in diseased population.

In conclusion, our data shows that the total counts of microvesicle populations were associated with stress-related markers - hair cortisol and blood serum MDA concentrations. Non-activated EMV count (i.e., not carrying CD62e) had no association with any of atherosclerosis risk factors except for CD105-positive microvesicles, which showed association with SBP. Expression of CD62e in various populations of EMV and ratio of $\mathrm{CD} 144^{+}$to $\mathrm{CD} 105^{+} / \mathrm{CD} 62 \mathrm{e}^{+}$ microvesicles were associated with increased LDL-C concentration as well as total cholesterol concentration in healthy young male population. The data suggests that CD $144^{+}$microvesicles have an association with chronic and oxidative stress markers and could be useful as a biomarker for early diagnostics of endothelial disorders.

\section{References}

1. Stocker R, Keaney JF. Role of oxidative modifications in atherosclerosis. Physiol Rev. 2004;84(4):1381-1478.

2. Mittal M, Siddiqui MR, Tran K, Reddy SP, Malik AB. Reactive oxygen species in inflammation and tissue injury. Antioxid Redox Signal. 2014; 20(7):1126-1167.

3. Matsuzawa Y, Lerman A. Endothelial dysfunction and coronary artery disease: Assessment, prognosis, and treatment. Coron Artery Dis. 2014;25(8):713-724.

4. Lee R, Margaritis M, Channon K, Antoniades C. Evaluating oxidative stress in human cardiovascular disease: Methodological aspects and considerations. Curr Med Chem. 2012;19(16):2504-2520.

5. Mastromonaco GF, Gunn K, McCurdy-Adams H, Edwards DB, Schulte-Hostedde Al. Validation and use of hair cortisol as a measure of chronic stress in eastern chipmunks (Tamias striatus). Conserv Physiol. 2014;2(1):cou055.

6. Schiro A, Wilkinson FL, Weston R, Smyth JV, Serracino-Inglott F, Alexander MY. Endothelial microparticles as conveyors of information in atherosclerotic disease. Atherosclerosis. 2014;234(2):295-302.

7. Paudel KR, Panth N, Kim D-W. Circulating endothelial microparticles: A key hallmark of atherosclerosis progression. Scientifica (Cairo). 2016; 2016:8514056.

8. Barteneva NS, Fasler-Kan E, Bernimoulin M, et al. Circulating microparticles: Square the circle. BMC Cell Biol. 2013;14:23.

9. Fairweather DL. Sex differences in inflammation during atherosclerosis. Clin Med Insights Cardiol. 2014;8(Suppl 3):49-59.

10. Khoschsorur GA, Winklhofer-Roob BM, Rabl H, et al. Evaluation of a sensitive HPLC method for the determination of malondialdehyde, and application of the method to different biological materials. Chromatographia. 2000;52(3):181.

11. Raul JS, Cirimele V, Ludes B, Kintz P. Detection of physiological concentrations of cortisol and cortisone in human hair. Clin Biochem. 2004;37(12):1105-1111.

12. De Palo EF, Antonelli G, Benetazzo A, Prearo M, Gatti R. Human saliva cortisone and cortisol simultaneous analysis using reverse phase HPLC technique. Clin Chim Acta. 2009;405(1-2):60-65.

13. Jin Z-G, Lungu AO, Xie L, Wang M, Wong C, Berk BC. Cyclophilin $A$ is a proinflammatory cytokine that activates endothelial cells. Arterioscler Thromb Vasc Biol. 2004;24(7):1186-1191.

14. Koga H, Sugiyama S, Kugiyama K, et al. Elevated levels of VE-cadherin-positive endothelial microparticles in patients with type 2 diabetes mellitus and coronary artery disease. J Am Coll Cardiol. 2005; 45(10):1622-1630.

15. Colombo E, Borgiani B, Verderio C, Furlan R. Microvesicles: Novel biomarkers for neurological disorders. Front Physiol. 2012;3:63.

16. Nozaki T, Sugiyama S, Koga H, et al. Significance of a multiple biomarkers strategy including endothelial dysfunction to improve risk stratification for cardiovascular events in patients at high risk for coronary heart disease. J Am Coll Cardiol. 2009;54(7):601-608.

17. Preston RA, Jy W, Jimenez JJ, et al. Effects of severe hypertension on endothelial and platelet microparticles. Hypertension. 2003;41(2): 211-217.

18. Li P, Qin C. Elevated circulating VE-cadherin + CD144 + endothelial microparticles in ischemic cerebrovascular disease. Thromb Res. 2015; 135(2):375-381.

19. Trappenburg MC, van Schilfgaarde $M$, Marchetti $M$, et al. Elevated procoagulant microparticles expressing endothelial and platelet markers in essential thrombocythemia. Haematologica. 2009;94(7): 911-918.

20. Eldh $\mathrm{M}$, Ekström $\mathrm{K}$, Valadi $\mathrm{H}$, et al. Exosomes communicate protective messages during oxidative stress: Possible role of exosomal shuttle RNA. PLoS One. 2010;5(12):e15353. 
21. Ren S, Fan X, Peng L, et al. Expression of NF-KB, CD68 and CD105 in carotid atherosclerotic plaque. J Thorac Dis. 2013;5(6):771-776.

22. Li C, Mollahan P, Baguneid MS, et al. Comparative study of neovascularization in atherosclerotic plaques using CD31, CD105 and TGF $\beta 1$. Pathobiology. 2006;73(4):192-197.

23. Mobarrez F, Antoniewicz L, Bosson JA, Kuhl J, Pisetsky DS, Lundbäck $M$. The effects of smoking on levels of endothelial progenitor cells and microparticles in the blood of healthy volunteers. PLoS One. 2014;9(2):e90314.
24. Berezin AE, Kremzer AA, Berezina TA, Martovitskaya YV. Pattern of circulating microparticles in chronic heart failure patients with metabolic syndrome: Relevance to neurohumoral and inflammatory activation. BBA Clin. 2015;4:69-75.

25. Kjærgaard AG, Dige A, Krog J, Tønnesen E, Wogensen L. Soluble adhesion molecules correlate with surface expression in an in vitro model of endothelial activation. Basic Clin Pharmacol Toxicol. 2013;113(4): 273-279.

26. Werner N, Wassmann S, Ahlers P, Kosiol S, Nickenig G. Circulating $\mathrm{CD} 31+$ /annexin $\mathrm{V}+$ apoptotic microparticles correlate with coronary endothelial function in patients with coronary artery disease. Arterioscler Thromb Vasc Biol. 2006;26(1):112-116. 